\title{
Penetrating Popliteal Vascular Injury: Surgical Management and Early Outcome During Current War in Taiz - Yemen
}

Abudar Abdo AL ganadi

Taiz University

Naseem Saeed Al-Ossabi ( $\square$ naseem.alawsabi@gmail.com )

Taiz University https://orcid.org/0000-0003-3083-8472

Ismail Samer Alshameri

Taiz University

Mamon K Al-Mekhlafi

INASP Yemen

Maha A Hizam

Taiz University

Abdulkafi M Shamsan

Taiz University

Research article

Keywords: Popliteal vascular injury, Penetrating injury, Amputation, Fasciotomy.

Posted Date: February 22nd, 2021

DOl: https://doi.org/10.21203/rs.3.rs-192242/v1

License: (9) (i) This work is licensed under a Creative Commons Attribution 4.0 International License.

Read Full License 


\section{Abstract}

Background: Popliteal vascular injury remains a challenging entity, and carries the greatest risk of limb loss among lower extremity vascular injuries. We aim to review our experience with complex penetrating popliteal vascular injuries, thereby focusing on therapeutic challenges, and early outcomes.

Methods: From September 2015 to December 2019, we managed total of 728 penetrating vascular injuries with 163 popliteal vascular injuries presented to Authority of Althawra hospital in Taiz. Of 125 patients, 103 patients were fulfilling the inclusion criteria. Variables were retrospectively collected included patient demographics, mechanism and type of injuries, limb ischemia time, type of vascular reconstruction, associated complications, limb salvage, and mortality.

Results: 157 vascular reconstructions were performed for 103 patients with penetrating popliteal vascular injuries, the majority 94 (91.3\%) were male. Mean age was $27.3 \pm 12.3$ years. Popliteal vascular injuries were the second most common accounting for $35 \%$ of lower extremity vascular injuries and $22.4 \%$ of the total vascular injuries. Nearly half $54(52.4 \%)$ of patients sustained complex popliteal vascular injuries (arterial and venous injuries), 31 (30.1\%) isolated arterial injuries, and 18 (17.5\%) isolated venous injuries. Management of vascular injury was repaired by interposition graft in $68(66 \%)$, end-to-end anastomosis in $16(15.5 \%)$, and venous patch in $1(1 \%)$. Venous injury was repaired in $53(51.4 \%)$ and ligated in 18 (17.5\%). Less than 6 hours from injury to completed revascularization was achieved in 58 (56.3\%) patients. The overall fasciotomy was $28(27.2 \%)$ which significantly increased length of hospital stays (17 days vs 7 days, $P=0.0003$ ). The overall limb-salvage rate in our study was $94.2 \%$. During the study period, the most common complication was 14 (13.6\%) wound infection, 14 (13.6\%) graft thrombosis, 6 (5.8\%) bleeding, 4 (3.9\%) graft infection. Early limb loss occurred in $6(5.8 \%)$ and the mortality rate was $(1.9 \%)$.

Conclusions: Wartime penetrating popliteal vascular injury is a real challenge. However, team approach and promptly vascular repair found to associate with a remarkable limb salvage rate of $94.2 \%$. We advocate repair of arterial injury with vein graft as the treatment of choice whenever possible.

\section{Introduction}

The popliteal artery is the second most commonly injured vessel in the lower extremity in which its injury remains a challenging entity and is frequently associated with high levels of morbidity and poor rates of limb salvage compared with other vascular injuries. $(1,2)$ There is a wide variation in the incidence, cause, and mechanism of vascular trauma depending on the local conditions.

In the current warfare conditions, vascular trauma represents $7-10 \%$ of total battle injuries.(3-5) Popliteal artery injuries (PAI) account for about $5-19 \%$ of extremity arterial injuries in civilians $(6,7)$ while in the military setting, the reported incidence of vascular injuries has changed significantly since World War I (WWI) until now. The rate in WWI was reported to be $0.4-1.3 \%$ and in WWII $0.96 \%$. The rate increased slightly during the Vietnam and Korean wars to $2 \%-3 \%$. However, the rate increased to $12 \%$ 
during the recent tours in Afghanistan and Iraq. Of these injuries, $66 \%$ occurring in the lower extremities of which PAlconstitute $50-60 \%$ of all extremity arterial injuries and had an increased rate of secondary amputation, probably as a result of the associated soft-tissue injuries that accompany improvised explosive device (IED) injury patterns.(8-12)

However, PAl has the highest rates of amputations amongst all lower extremity vascular injuries. Despite technical advancements and the lessons learned during the war era $(13,14) \cdot(15)$ the associated amputation rates are high $(10-16 \%)(13,14,16-18)$ although in the military population remain at approximately $30 \%$, whereas range between $14.5-25 \%$ in the literature for civilians. $(9,19)$ The practice of early vascular repair over simple ligation has greatly improved limb salvage rates.(19-22)

Since the first moment of Yemeni revolution in February 2011, an exponential rise in the number of vascular injuries in Taiz city in Yemen, in which Yemen international hospital received 63 cases of vascular injuries with $10(16 \%)$ patients of popliteal vessels injury that present critical challenges in resource-limited settings of developing countries.(3) Ideally, war injuries should be treated by surgeons having military surgery experience. In fact, civilian surgeons may find themselves trapped in wars practicing military surgery without prior training or experience in this field.(15) The purpose of this study was to review our recent experience with penetrating popliteal vascular injuries in Taiz -Yemen, thereby focusing on surgical management, and early outcomes and to highlight lessons learned from that period.

\section{Material And Method}

\section{Data Collection}

From September 2015 to December 2019, we managed total of 728 penetrating vascular injuries with 163 (125 patients) popliteal vascular injuries presented to Authority of Althawra hospital in Taiz-Yemen. Of 125 patients, 103 patients were fulfilling the inclusion criteria. Variables were retrospectively collected included patient demographics, mechanism and type of injuries, limb ischemia time, type of vascular reconstruction, associated complications, limb salvage, and mortality.

Any of the following was considered criteria for exclusion: presented with late complications of PAI (pseudoaneurysms and arteriovenous fistulas), primary traumatic amputation of lower limb associated with PAl, blunt PAl, iatrogenic PAl, and incomplete or missed file data during the study period.

All patients were resuscitated in emergency room according to Advanced Trauma Life Support protocols in the hospital field. The diagnosis of popliteal vascular injuries was based on clinical examination and hand-held Doppler. Hard signs findings of vascular injury like (distal ischemia, pulsatile bleeding, expanding hematoma, palpable thrill, or bruit) were indications for immediate surgical exploration and repair. For soft signs of vascular injury and no immediate threat to life or limb, patients were admitted for close observation and frequent vascular examination, as we were unable to send patients for computed tomography angiography because of limited sources in the city related to war. Routine $\mathrm{x}$ rays of the lower 
extremity were performed on arrival to assess for bony fractures or dislocation. All patients were diagnosed and operated on within 24 hours. Time of limb ischemia was defined as the time from injury to revascularization. Limb salvage was defined as the presence of a viable limb at 1 month after injury, regardless of functional outcome.

Our approach was to perform surgical revascularization as soon as the vascular injury was recognized. Operative exploration of injured vessels was performed via standard incisions, distal and proximal control. Flow and backflow were assessed, and we routinely passed an embolectomy catheter to proximal and distal segments to perform thrombectomy followed by the flushing of the distal segment with heparinized saline. This was followed by definitive repair. Direct end-to-end anastomosis was performed if approximation of debrided arterial ends were free of tension. When this was not possible, IPVG, using autologous reversed long saphenous vein from the contralateral limb, was done. The prosthetic graft was not used in our study.

Deep venous injuries were repaired rather than ligated if patients were hemodynamically stable and when judged necessary. The venous return was restored after arterial repair. Vascular reconstruction was performed before orthopedic stabilization whenever possible. We did not use temporary intravascular shunting (TIVS). We routinely performed calf fasciotomy (4 compartment via 2 incisions), when compartment syndrome was anticipated. Compartment syndrome was based primarily on the clinical finding of tense calf swelling.

Postoperatively, Frequent monitoring and vascular checks (eg, pulse presence, quality, and capillary refill) continue for the first 24-48 hours. The injured lower limb was kept elevated and wrapped with a compressed bandage. Early ambulation (within the first 24-48 hours) was encouraged. All patients received prophylactic antibiotics, which were continued postoperatively for 3-5 days unless prolonged use was dictated by the presence of obvious contamination or infection. Low molecular weight heparin (LMWH) was administered throughout hospital confinement. Patients with arterial injuries received antiplatelet therapy with 100 -mg acetylsalicylic acid routine 90 days postoperatively. Complications and outcomes were reviewed through OPD appointment and telephone survey.

\section{Data and statistical analysis}

This study is a retrospective review. The major endpoints are overall limb-salvage and mortality rates. Subgroup analysis was performed for secondary endpoints including fasciotomy and vascular complications. Numerical values were expressed as mean \pm standard deviation. Continuous data were compared with unpaired Student's t-tests. All statistical analyzes were performed using SPSS Statistics 24.0. Variables were compared by using analysis of Chi-square analysis or Fisher exact test. P-values $\leq$ 0.05 were considered statistically significant.

\section{Results}


From September 2015 to December 2019, we managed a total of 728 vascular injuries presented to our hospital. During that period, 125 patients presented with 163 popliteal vascular injuries.

Twenty-tow patients were excluded from the study, as they were not candidate for the inclusion criteria. Among them: blunt injury (one patient), iatrogenic injury (one patient), late presentations; including the delayed aneurysms ( 3 patients), and arteriovenous fistulas (one patient), branches injury (5 patients), and incomplete file data ( 2 patients). Mean age was $27.3 \pm 12.3$ years and the majority of patients were males 94 (91.3\%). There were 84 (81.6\%) patients who sustained a penetrating injury due to high-velocity gunshot and 19 (18.4\%) were blast injuries. Popliteal vascular injuries were the second most common accounting for $35 \%$ of lower extremity vascular injuries and $22.4 \%$ of the total vascular injuries. Demographic data are summarized in Table 1.

Table 1

Patient demographics data

\begin{tabular}{|llc|}
\hline Patient demographics & Number & $\%$ \\
\hline Age (years) & $27.27 \pm 12.3$ \\
\hline Gender & & \\
Male & 94 & 91.3 \\
\hline Female & 9 & 8.7 \\
\hline Mechanism & & \\
\hline Gunshot injury & 19 & 18.4 \\
\hline Blast injuries & 84 & 81.6 \\
\hline
\end{tabular}

Total of 157 popliteal vascular injuries were classified as 85 (82.2\%) PAI and 72 (69.9\%) PVI Fifty-four (52.4\%) patients had combined ipsilateral popliteal arterial and venous injuries. Regarding intra-operative findings, type of arterial injury was classified into 57 (55.3\%) completely transected, 26 (25.2\%) partially transected, and 2 (1.9\%) contused with thrombosis and/or intimal injury. PVI finding were; 43 (41.7\%) completely transected, 28 (27.2\%) partially transected, and 1 (1\%) contusion, which was managed medically with anticoagulation.

All PAI were managed with debridement and definitive repair. The optimal technical repair was used for each injury: 68 (66\%) RSVG, 16 (15.5\%) end-to-end anastomosis, and 1 (1\%) venous patch. PVI were repaired in 14 (13.6\%) IPVG, 37 (35.9\%) end-to-end anastomosis, 18 (17.5\%) ligation, 2 (1.9\%) venorraphy, $1(1 \%)$ observation with anticoagulation (Table 2). Less than 6 hours from injury to completed revascularization was achieved in $58(56.3 \%)$ patients.

The overall fasciotomy was $28(27.2 \%)$ of which 16 (15.5\%) were prophylactically done immediately post vascular reperfusion and $12(11.7 \%)$ were therapeutic done after clinical diagnosis of compartment syndrome. Associated orthopedic injuries in 63 (61.2\%) patients; 50 (48.5\%) patients required external 
stabilization, 3 (2.9\%) patients were fixed with open reduction and internal fixation (ORIF), and 10 (9.7\%) patients by plaster casts. Adjacent concomitant injuries included nerve injury in 40 (38.8\%) patients, significant soft tissue loss requiring skin or muscle flaps in $27(26.2 \%)$ patients, and associated major body injuries in $15(14.6 \%)$ patients (Table 3$)$.

Table 2

Methods of arterial and venous repair, patients, $n=103$

\begin{tabular}{|lll|}
\hline \multicolumn{2}{|c|}{ Number } & $\%$ \\
\hline Type of repair Popliteal artery & 68 \\
\hline Saphenous interposition grafting & 68 & 66 \\
\hline End-to-end anastomosis & 16 & 15.5 \\
\hline Venous patch & 1 & 1 \\
\hline Type of repair Popliteal vein & & \\
\hline Saphenous interposition grafting & 14 & 13.6 \\
\hline End-to-end anastomosis & 37 & 35.9 \\
\hline Venoraphy & 2 & 1.9 \\
\hline Ligation & 18 & 17.5 \\
\hline Conservative treatment & 1 & 1 \\
\hline TOTAL & 157 & \\
\hline
\end{tabular}


Table 3

Adjacent Associated injuries, patients, $\mathrm{n}=103$

\begin{tabular}{|lll|}
\hline Associated injury & Number & $\%$ \\
\hline Fracture & 63 & 61.2 \\
\hline Distal femur & 48 & 46.6 \\
\hline Proximal tibia & 11 & 10.7 \\
\hline Proximal tibia and fibula & 2 & 1.9 \\
\hline Proximal fibula & 2 & 1.9 \\
\hline Nerve injury & 40 & 38.8 \\
\hline Sciatic nerve & 10 & 9.7 \\
\hline Tibial nerve & 23 & 22.3 \\
\hline Common peroneal nerve & 7 & 6.8 \\
\hline Significant soft tissue loss & 27 & $\mathbf{2 6 . 2}$ \\
\hline Major body injury & 15 & 14.6 \\
\hline Chest & 3 & 2.9 \\
\hline Abdomen & 6 & 5.8 \\
\hline Contralateral lower limb & 6 & 5.8 \\
\hline
\end{tabular}

The overall limb-salvage rate in this study was $94.2 \%$. 30-days complications in the survival group were: 14 (13.6\%) wound infection, 14 (13.6\%) graft thrombosis, 6 (5.8\%) bleeding and $\backslash$ or hematoma collection, 4 (3.9\%) graft infection, 6 (5.8\%) above-knee amputations, and pulmonary embolism developed in one case (Table 4). Six patients had above-knee amputation after revascularization. Among them, 2 patients were associated with massive soft-tissue injuries and preoperative neurologic impairment in the injured limb. In spite of good vascular repair, patients had a recurrent infection and sensory and motor loss, they later developed wounds infection and did not regain motor or sensory function in the reconstructed limb. Two patients had failed revascularization and the last 2 patients had a severe infection and graft thrombosis.

All vascular repairs were patent upon hospital discharge. Seventy-five patients (72.8\%) required ICU admission, with a mean length of stay of $1.1 \pm 1.4$ days. The overall mean length of hospitalization was $9.96 \pm 9$.6days. The hospital stay was significantly longer in patients who had fasciotomy and wound infection compared to patients without fasciotomy or infection (7 days vs 17 days, 8 days vs 21 days, $P$ $=0.0003, P=0.02$ respectively).

The overall mortality rate for patients who sustained penetrating popliteal vascular injuries was $1.9 \%$ (two patients). The first patient had missed PAl and died 7 hours post vascular repair due to hemorrhagic 
shock, the second patient developed a pulmonary embolism and died 3rd post-operative day.

Table 4

Postoperative complications \& 30-day outcome, patients, $n=103$

\begin{tabular}{|lll|}
\hline & Number & $\%$ \\
\hline Postoperative complications & & \\
\hline Graft thrombosis & 14 & 13.6 \\
\hline Wound infection & 14 & 13.6 \\
\hline Compartment syndrome & 12 & 11.7 \\
\hline Bleeding and lor hematoma & 6 & 5.8 \\
\hline Significant Lower limb edema & 8 & 7.8 \\
\hline Graft infection & 4 & 3.9 \\
\hline Limb gangrene & 4 & 3.9 \\
\hline Ligation of graft & 3 & 2.9 \\
\hline Anastomotic Aneurysm & 2 & 1.9 \\
\hline Myocardial infarction & 1 & 1 \\
\hline Acute kidney injury & 1 & 1 \\
\hline pulmonary embolism & 1 & 1 \\
\hline Pneumonia & 2 & 1.9 \\
\hline 30-day outcome & & \\
\hline Mortality & 2 & 1.9 \\
\hline Amputations & $6.1 \pm 1.4$ & \\
\hline Limb salvage & $9.96 \pm 9.6$ & \\
\hline ICU stay (days)* & & \\
\hline Hospital stay (days)* & & \\
\hline * mean \pm SD & & \\
\hline
\end{tabular}

\section{Discussion}

Austere environments, the lack of usual supplies, and exposure to horrific injuries all affirm Debakey's comment that "war is never a cheerful business.(13) Now, as we approach this fifth year of the war in Yemen, we continue to evaluate and report the management of wartime popliteal vascular injury in an 
effort to enhance the care of such injuries for both military and civilian settings. This report comments on type of injury, management, repair technique, and early outcome.

In this study, 103 patients with popliteal vascular injuries were recorded and most of them were active young patients (mean age was $27.3 \pm 12.3$ years with $89.3 \%$ being less than 45 years) thus, optimal management to control bleeding and reestablish circulation is crucial. The management of complex injuries involving vascular and skeletal elements of the lower extremity remains challenging and still incurs a high incidence of limb loss and morbidity.(23-27) The management of military vascular trauma has changed considerably as a result of the wars of the 20th century and the significant contributions of Debakey, Hughes, Rich, and others. $(13,14,28)$

Gunshot and blast injuries caused the penetrating popliteal vascular injuries in our study. In which gunshot wounds from high-velocity weapons accounted for the majority $(81.6 \%)$ of popliteal vascular injuries, producing deep cavity wounds frequently associated with fracture and neurovascular injury. The majority of penetrating PAl can be detected by initial examination, Wagner et al.(29) found $55 \%$ of limbs preoperatively had clinical ischemia, and capillary refill was considered an unreliable measurement of distal perfusion.(29) Some signs including motor and sensory dysfunction, pain, and pallor are signs of late distal ischemia and may delay appropriate management. Unmistakable frank hemorrhage and "hard" signs of vascular injury, including a pulsatile expanding hematoma, pulselessness, presence of bruit or thrill, and signs of distal ischemia require immediate surgical intervention.

Repair of PAl by end-to-end anastomosis was used only in $15(14.6 \%)$ patients. Military weapons often produce a deep cavitary injury and segmental arterial loss thus, a tension-free anastomosis cannot be achieved. Mobilization of the arterial ends in a young patient with nondiseased arteries often allows the construction of a tensionless primary arterial repair.(30) PAI repaired with a RSVG comprised 68 (66\%) most of the arterial repairs in our report, therefore an IPVG is the most used type of repair, preferably utilizing a contralateral autogenous saphenous vein. Vein graft was covered by healthy tissue or routed around the zone of injury. Similarly, most studies recommended using the IPVG, where's autologous vein graft remains the most durable and effective means of vascular repair.(31) Prosthetic grafts are typically avoided because of their lower rates of patency, $(25,29)$ we don't use prosthetic graft in our practice mainly due to limited sources in our city.

Our practice with concurrent venous injuries is to repair rather than ligated whenever possible. Of $72 \mathrm{PVI}$, the majority $53(51.4 \%)$ were repaired, 37 (35.9\%) by end-to-end anastomosis, $14(13.6 \%)$ by IPVG, 2 $(1.9 \%)$ venoraphy repair, and one case had contused vein that observed without intervention. The remaining 18 (17.5\%) PVI were treated by ligation. Although repair of accompanying venous injury is controversial, venous repair may enhance venous drainage and, therefore decreased compartment pressure and eventual limb loss. $(25,29,32)$ However, others have found no vascular-related complications from venous ligation. $(27,33)$ In our patients, we recommend venous repair in stable patients and ligation as damage control in hemodynamically unstable patients. Venous graft should be maintained as patent in particularly for the first 72 hours. Venous circulation may be provided by 
collaterals even if it is occluded after this period. Venous repair is required especially for diffuse soft tissue defects that may prevent the development of venous collateral circulation.(10) Restoration of venous circulation in order to enhance the patency of arterial anastomoses and to reduce the risk of late venous stasis may be more important at the popliteal region than any other site.(34) In contrast, there are also reports indicating that venous ligation does not have an important sequel and venous ligation is tolerated well even at the popliteal region and does not have a negative impact on arterial circulation.(10, 33)

A major concern is that repair of venous injuries will result in vein thrombosis and subsequent pulmonary emboli, although support for this scenario is somewhat anecdotal.(35) In the largest recent study, they have found this to be the contrary; in fact, the risk of pulmonary emboli is low in venous repair compare to venous ligation or equivalent.(36) In our study result, pulmonary embolism was recorded in one (1\%) patient, in which venous injury was repaired by IPVG. Regardless of long-term results, venous patency during the initial 2 weeks after the injury perhaps improves patency rates in a new arterial anastomosis before development of collateral venous canals. $(37,38)$ Moore et al.(39) advocate that venous patency for 2 weeks after reconstruction virtually assures long-term patency. Finally, Reagan et al.(36) reported their analysis of a review of more than 100 traumatic military venous injuries. They conclude that management of vein repair versus ligation for traumatic venous injury remains a controversy. In an ideal setting, venous injuries should be repaired when possible and tolerated by the patient especially in a watershed area, as in popliteal venous injury. Repair is especially encouraged to ameliorate the high risk of leg phlegmasia or fascial edema. They found also no significantly different infection rates for venous injuries patients who were treated by ligation or venous repair. In our study, there were no significantly different infection rates for venous injuries patients who were treated by ligation or venous repair $(p=$ $0.24)$.

It is a controversial issue that which one should be repaired first for patients that have both popliteal artery and popliteal vein injuries. Some indicated that first venous and then arterial repair should be done and thus venous circulation should be improved after arterial revascularization.(40) However some authors reported that arterial repair should be done first in order to reduce the duration of ischemia.(41) For our report, first arterial repair was done and thus ischemia duration was kept as short as possible. The shunt was not used because we thought venous circulation was provided partly by collaterals until venous repair was done.

Furthermore, our results confirm that a good limb-salvage rate (94.2\%) is achieved without the use of TIVS if revascularization is performed as soon as the arterial injury is recognized. The placement of an TIVS would be an additional step with no real benefits and may potentially cause vessel complications such as dissection or thrombosis.(42) In support of our contention, other large series have found the use of TIVS not helpful. $(27,29,43)$ However, TIVS may be useful as part of a "damage-control" strategy for patients who are too "unstable" to undergo immediate vascular reconstruction because of other lifethreatening injuries.(44) In this setting, limb perfusion can be maintained through the TIVS until the patient's condition ameliorates at which time vascular repair can be performed.

Page 10/19 
More than half of the vascular injuries (61.2\%) were associated with long-bone fractures in our report. The timing of orthopedic fixation in concomitant bone injury is a source of debate. Prior skeletal fixation is strongly advocated in some series, $(45,46)$ while more recent reports have highlighted the importance of reducing ischemia time by proceeding with vascular reconstruction first.(27, 47) Wolf et al.(48) reduced ischemia time by using TIVS and then performing orthopedic fixation before vascular reconstruction. In our practice, we use vascular repairs firstly in all cases followed by orthopedic fixations on a stable base. Based on this experience and that of others, we advocate that definitive arterial reconstruction should precede orthopedic intervention for combined complex lower-extremity injuries. $(27,47,49)$

Of the 103 patients, 28 (27.2\%) patients had associated complication in our study. The most common complication was wound infection (13.6\%) and graft thrombosis (13.6\%), lower than that reported by Fox et al.(50) the overall complication rate among 30 casualties who suffered a major complication or failed attempted limb salvage was $65 \%$ included infection (26\%), Ratnayake et al.(51) the most common complication was wound infection (33\%) and early graft thromboses (24\%), and those of past conflicts often related to infection and graft occlusion. $(5,13,14,50,52,53)$

Popliteal vascular injuries are associated with higher rates of compartment syndrome. Predominant risk factors included prolonged ischemia $(>6 \mathrm{~h}$ ), combined vascular and skeletal injuries, or venous ligation. (23) In our experience, 2-incision fasciotomies were usually performed at the initial operation immediately after restoration of blood perfusion. The technique for a single-incision fasciotomy is a well-described alternative for adequate decompression of the lower extremity however, a more involved surgical dissection is required.(54) Also, the decision to perform fasciotomies was clinical one and its liberal use has been recommended by some groups. $(19,23,42,55)$

The overall fasciotomy rate in this study $(27.2 \%)$ is superior to previously reported series, $(27,29,42,56)$ and NTDB (50\%).(19) The liberal use of fasciotomies appears to be associated with lower rates of amputation but the fasciotomy wounds themselves are a source of morbidity. In fact, the length of stay was significantly longer in patients who had fasciotomy compared with no fasciotomy (17 versus 7 days, $p=0.0003)$. We acknowledge in this series, the fasciotomy wounds were associated with increased morbidity and longer length of hospital stay.

In our study, we found low amputation rates of only $5.8 \%$, superior to previous studies $(11 \%$ for penetrating injuries) and other series ranging as high as $71 \% .(19,55)$ Hafez et al.(27) showed amputation rates of $16 \%$ in a series of 550 patients with lower extremity arterial injury, of which $31 \%$ corresponded to PAI. Nair et al.(25) reported a series of 117 popliteal artery gunshot wounds with $27 \%$ and $50 \%$ amputation rates for low and high-velocity injuries, respectively.

We found that amputation rate was significantly higher in patients who had wound infection and Fasciotomy ( $P=0.007, P=0.025$ respectively). In contrast to previous reports, we found no good preoperative predictors for limb loss, including venous ligation, associated facture, ischemic time (mean $5.6 \pm 2.6$ hours), and compartment syndrome $(P=0.31, P=0.48, P=0.38, P=0.14$ respectively). Although it is generally accepted that skeletal muscles can tolerate ischemia up to 6 hours, we found that the 
ischemic time alone cannot be used to predict limb viability. Prolonged ischemia is a well-recognized predictor of cell death, but the tolerance period varies between persons, depending on the severity of the ischemia and the presence of collateral flow. So, decreasing ischemic time from admission to restoration of perfusion as close to 6 hours as possible may improve outcomes by increased limb salvage and decreased amputation. The mortality in this series was $1.9 \%$ which is similar to previous studies ranging from 1 to $9 \%$. $(22,27,57)$

\section{Limitations of the study:}

First, this study is retrospective and refers to penetrating injury to the most complicated zone of lower limbt. Second, Database system are not matured enough and lots of information regarding ISS, GCS and MESS are missing or not exist. The often multiple admissions and emergent operating mode with and lack of registrars and uniform data collections prevent important details from being promptly recorded. Finally, there were no extensive diagnostic radiological procedures and wounds were explored in the operating theatre as soon as possible depending mainly on the clinical findings. Angiography / Endovascular means was not used in our series. Therefore, it is possible that occult vascular injuries have been possibly missed and those usually present later. Despite these limitations, the overall observations herein are significant and add knowledge to report in previous wartime experiences, we think that it is very important to share this information with others.

\section{Conclusions}

Wartime penetrating popliteal vascular injury is a real challenge. However, team approach and promptly vascular repair found to associate with a remarkable limb salvage rate of $94.2 \%$. This study represents the first analysis of popliteal vascular injuries during the contemporary war in Taiz city in Yemen. We advocate repair of arterial injury with vein graft as the treatment of choice whenever possible.

\section{List Of Abbreviations}




\begin{tabular}{ll} 
WWI & World War I \\
\hline WWII & World War II \\
\hline IED & Improvised Explosive Device \\
\hline PAI & Popliteal artery injuries \\
\hline PVI & Popliteal Vein Injuries \\
\hline TIVS & Temporary Intravascular Shunting \\
\hline OPD & Out Patient Department \\
\hline LMWH & Low Molecular Weight Heparin \\
\hline IPVG & Interposation Venis Graft \\
\hline NTDB & National Trauma Data Bank
\end{tabular}

\section{Declarations}

Ethics approval and consent to participate 


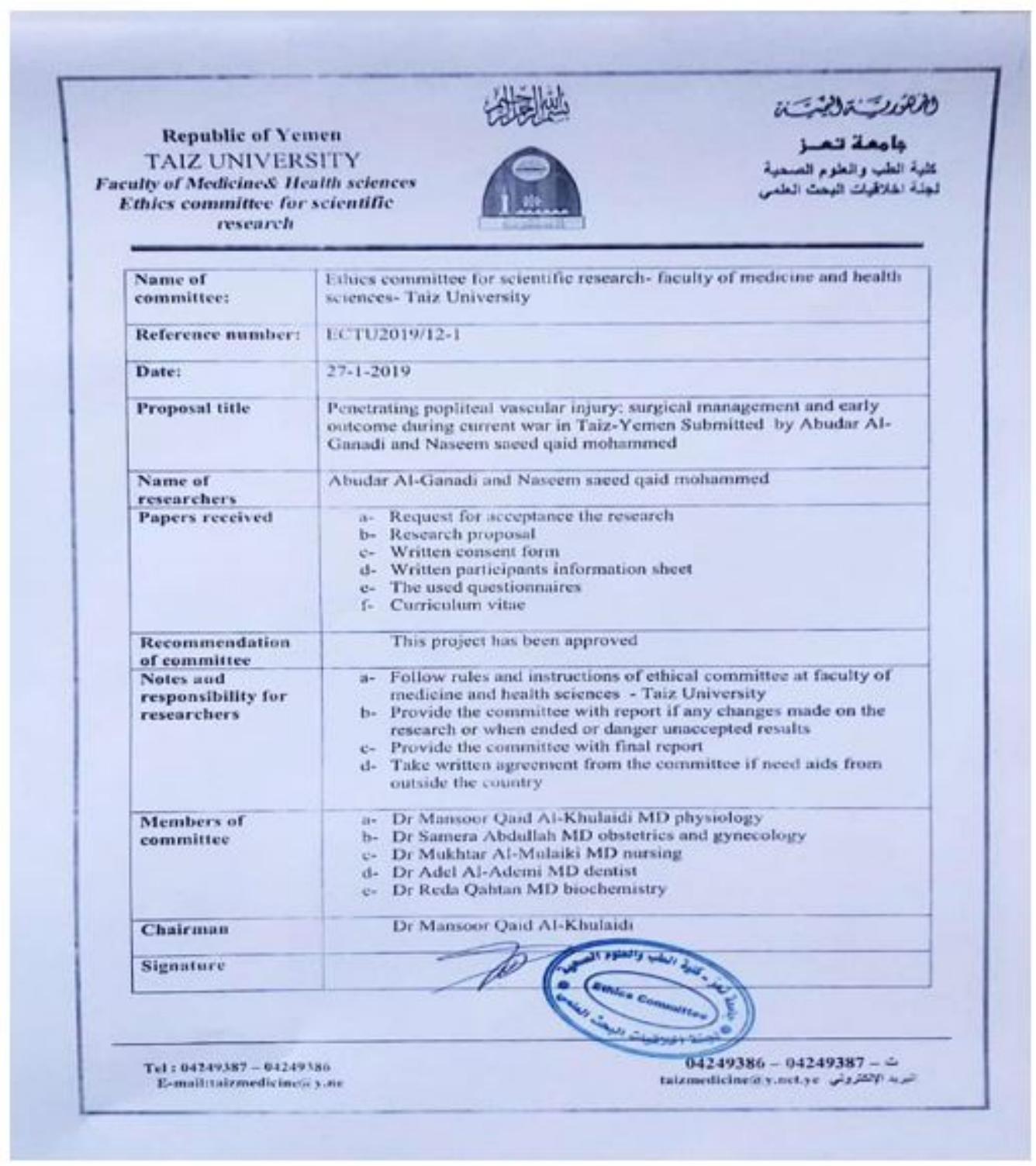

\section{Consent for publication}

“Not applicable”

\section{Availability of data and materials}

The datasets generated during and/or analysed during the current study are available from the corresponding author on reasonable request.

\section{Competing interests}

"The authors declare that they have no competing interests"

\section{Funding}

"Not applicable" 


\section{Authors' contributions}

Conception and design: NS, AA

Analysis and interpretation: NS, AA

Data collection: NS, IS, MK

Writing the article: NS, AA

Critical revision of the article: NS, AA, IS, MK, MA, AM

Final approval of the article: NS, AA, IA, MK, MA, AM

Statistical analysis: NA, AA,IS

Obtained funding: Not applicable

Overall responsibility: NS

All authors have read and approved the final version of the manuscript.

\section{Acknowledgements}

The authors would like to acknowledge and thank all of the surgeons, nurses, and medical personnel who worked selflessly to care for these patients. The authors would like to thank $\operatorname{Dr} A$. al ademi for his assistance in concept and desine.

\section{Authors' information}

\section{Affiliations:}

Department of Cardiovascular surgery, Authority of Althawra Hospital, Faculty of Medicine, Taiz University, Taiz, Yemen

\section{Abudar Abdo Al-Ganadi}

Department of General and Vascular Surgery, Authority of Althawra Hospital, Faculty of Medicine, Taiz University, Taiz, Yemen

\section{Naseem Saeed Al-Ossabi \& Ismail Samer Al-Shameri \& Mamon K. Al-Mekhlafi}

Department of General and Vascular Surgery, Authority of Althawra Hospital, Faculty of Medicine, Taiz University

Maha Abdullh Hizam \& Abdulkafi Mohammed Shamsan 


\section{References}

1. Hossny A, Ed F. Blunt popliteal artery injury with complete lower limb ischemia: Is routine use of temporary intraluminal arterial shunt justified? J Vasc Surg. 2004;17-21.

2. Starnes BW, Bruce JM. Popliteal Artery Trauma in a Forward Deployed Mobile Army Surgical Hospital: Lessons Learned from the War in Kosovo. J Trauma Inj Infect Crit Care. 2000;48(6):11447.

3. Al-ganadi A. Management of Vascular Injury during Current Peaceful Yemeni Revolution. Ann Vasc Surg [Internet]. 2015;29(8):1575-80. Available from: http://dx.doi.org/10.1016/j.avsg.2015.06.075

4. Jawas A, Abbas AK, Nazzal M, Albader M, Abu-zidan FM. Management of war-related vascular injuries: experience from the second gulf war. World J Emerg Surg. 2013;8:22:1-5.

5. Fox CJ, Gillespie DL, Donnell SDO, Rasmussen TE, Goff JM, Johnson CA, et al. Contemporary management of wartime vascular trauma. J Vasc Surg. 2005;41(4):638-44.

6. Feliciano DV MK et al. Five - year experience with PTFE grafts in vascular wounds. J Trauma. 25:71 $-82$.

7. Baker SP OB. Injury severity score: an update. JTrauma. 1976;16(11):882-5.

8. Manna GHHB. Vascular Extremity Trauma -. StatPearls - NCBI Bookshelf.

9. Dua A, Patel B, Desai SS, Holcomb JB. Comparison of military and civilian popliteal artery trauma outcomes. J Vasc Surg [Internet]. 2009;59(6):1628-32. Available from: http://dx.doi.org/10.1016/j.jvs.2013.12.037

10. Ekim H, Basel H, Odabasi D. Management of traumatic popliteal vein injuries. Injury [Internet]. 2011;43(9):1482-5. Available from: http://dx.doi.org/10.1016/j.injury.2011.01.016

11. Dennis JW, Frykberg ER, C M. New perspectives on the management of penetrating trauma in proximity to major limb arteries. 1989;84-93.

12. Sciarretta JD, Macedo FIB, Otero CA, Figueroa JN, Pizano LR, Namias N. Management of traumatic popliteal vascular injuries in a level I trauma center: A 6-year experience. Int J Surg [Internet]. 2015;18(February):136-41. Available from: http://dx.doi.org/10.1016/j.ijsu.2015.04.056

13. DeBakey ME SF. Battle injuries of the arteries in World War Il; an analysis of 2,471 cases. Ann Surg. 1946;123(4):534-79.

14. Rich LTCNM, Baugh COLJH, Hughes BGCW. Popliteal Artery Injuries in Vietnam. Am J Surg. 1969;118(October):531-4.

15. Frcs $A B$, Frcs JM. War in juries during the Gulf War: experience of a teaching hospital in Kuwait. Ann R Coll Surg Engl. 1994;127(76):407-11.

16. CW. H. Acute vascular trauma in Korean War casualties; an analysis of 180 cases. Surg Gynecol Obs. 1954;1(99):91-100.

17. Anahita Dua, Bhavin Patel, John F. Kragh, Jr., John B. Holcomb CJF. Long-term follow-up and amputation-free survival in 497 casualties with combat-related vascular injuries and damage-control 
resuscitation. J Trauma Acute Care Surg. 2012;73(6):1517-24.

18. Dua A, Desai SS, Shah JO, Lasky RE, Charlton-ouw KM, Azizzadeh A, et al. Outcome Predictors of Limb Salvage in Traumatic Popliteal Artery Injury. Ann Vasc Surg [Internet]. 2014;28(1):108-14. Available from: http://dx.doi.org/10.1016/j.avsg.2013.06.017

19. Mullenix PS, Steele SR, Andersen CA, Starnes BW, Salim A, Martin MJ. Limb salvage and outcomes among patients with traumatic popliteal vascular injury: An analysis of the National Trauma Data Bank. J Vasc Surg. 2006;44(1):94-100.

20. Perkins ZB, Yet B, Glasgow S, Cole E, Marsh W, Brohi K et al. Meta-analysis of prognostic factors for amputation following surgical repair of lower extremity vascular trauma. $\mathrm{Br} \mathrm{J}$ Surg. 2015;102(5):436-50.

21. Parker S, Handa A, Deakin M SE. Knee dislocation and vascular injury: 4 year experience at a UK major trauma Centre and vascular hub. Injury. 2016;47(3):752-6.

22. Kauvar D, Sarfati M KL. National trauma databank analysis of mortality and limb loss in isolated lower extremity vascular trauma. J Vasc Surg. 2011;53(6):1598-603.

23. ER. F. Popliteal vascular injuries. Surg Clin North Am. 2002;82(1):67-89.

24. Moniz MP OM. Concomitant orthopedic and vascular injuries as predictors for limb loss in blunt lower extremity trauma. Am Surg. 1997;63:24-9.

25. Nair R, Abdool-Carrim ATO, Robbs J V. Gunshot injuries of the popliteal artery. Br J Surg. 2000;87(5):602-7.

26. SG. S. Popliteal artery trauma in a rural level I trauma center. Am Surg. 2003;(; discussion 90.).

27. Hafez HM, Woolgar J, Robbs J V. Lower extremity arterial injury: Results of 550 cases and review of risk factors associated with limb loss. J Vasc Surg. 2001;33(6):1212-9.

28. Woodward MEB, Darrin CW, Colonel L, Bowser AN, Cox MW. Penetrating femoropopliteal injury during modern warfare: Experience of the Balad Vascular Registry. 2007;1259-65.

29. Wagner WH, Calkins ER, Weaver FA, Goodwin JA, Myles RA, Yellin AE. Blunt popliteal artery trauma: One hundred consecutive injuries. J Vasc Surg. 1988;7(5):736-48.

30. Rich NM HC. The fate of prosthetic material used to repair vascular injuries in contaminated wounds. J Trauma. 1972;12(6):459-67.

31. Rich NM, Rhee P. An historical tour of vascular injury management: From its inception to the new millennium. Surg Clin North Am [Internet]. 2001;81(6):1199-215. Available from: http://dx.doi.org/10.1016/S0039-6109(01)80005-0

32. DC. R. Popliteal artery injuries. Vasc Endovascular Surg. 1983;17(189-94).

33. Jay A. Yelon TMS. Venous injuries of the lower extremities and pelvis: repair versus ligation. $J$ Trauma. 1992;33(4):532-8.

34. Rich NM, Hobson RW II, Collins GJ AC. The effect of acute popliteal venous interruption. Ann Surg. 1976;183(4):365-8. 
35. Smith LM, Block EF, Buechter KJ, Draughn DC, Watson D HW. The natural history of extremity venous repair performed for trauma. Am Surg. 1999;65(2):116-120.

36. Quan RW, Gillespie DL, Stuart RP, Chang AS, Whittaker DR, Fox CJ. The effect of vein repair on the risk of venous thromboembolic events: A review of more than 100 traumatic military venous injuries. J Vasc Surg. 2008;47(3):571-7.

37. Phifer TJ, Gerlock AJ, Rich NM et al. Long-term patency of venous repairs demonstrated by venography. J Trauma. 1983;25:432-46.

38. Parry NG, Feliciano D V., Burke RM, Cava RA, Nicholas JM, Dente CJ, et al. Management and shortterm patency of lower extremity venous injuries with various repairs. Am J Surg. 2003;186(6):631-5.

39. Moore TC TN. Experimental replacement and bypass of a large veins. Bull Soc Intern Chir. 3:274-82.

40. Lim LT, Michuda MS, Flanigan DP PA. Popliteal artery trauma: 31 consecutive cases without amputation. Arch Surg. 1980;115.

41. Khalil IM, Livingston DH. Intravascular shunts in complex lower limb trauma. J Vasc Surg. 1986;4(6):582-7.

42. Huynh TTT, D M, Pham M, D M, Griffın LW, Sc B, et al. Management of distal femoral and popliteal arterial injuries: an update. Am J Surg. 2006;192:773-8.

43. Starr, Adam J. MD; Hunt, John L. MD; Reinert CMM. Treatment of femur fracture with associated vascular injury. J Trauma Inj Infect Crit Care. 1996;40(1):17-21.

44. Granchi T, Schmittling Z, Vasquez J, Schreiber M. Prolonged Use of Intraluminal Arterial Shunts Without Systemic Anticoagulation. Am J Surg. 2001;180(DECEMBER):493-7.

45. Burg A, Nachum G, Salai M, Haviv B, Heller S, Velkes S, et al. Treating Civilian Gunshot Wounds to the Extremities in a Level 1 Trauma Center: Our Experience and Recommendations. IMAJ. 2009;11(september):546-51.

46. Singh D, Rk P. Management Of Peripheral Vascular Trauma: Our Experience. Internet J Surg. 2004;7(1):1-7.

47. Mchenry MAJTP, Holcomb LTCJB, Aoki N, Lindsey RW. Fractures with Major Vascular Injuries from Gunshot Wounds: Implications of Surgical Sequence. J Trauma. 2002;53(4):717-21.

48. Wolf YG RA. Vascular trauma in high-velocity gunshot wounds and shrapnel-blast injuries in Israel. Surg Clin North Am. 2002;82(1):237-44.

49. DF. B. Vascular injury associated with extremity trauma. Clin Orthop Relat Res. 1995;318(September):117-24.

50. Fox CJ, Perkins JG, Kragh JF, Singh NN, Patel B, Ficke JR. Popliteal Artery Repair in Massively Transfused Military Trauma Casualties: A Pursuit to Save Life and Limb. J TRAUMA® Inj Infect Crit Care. 2010;69(1):123-34.

51. Ratnayake A, Samarasinghe B, Bala M. Outcomes of popliteal vascular injuries at Sri Lankan warfront military hospital: Case series of 44 cases. Injury [Internet]. 2014;45(5):879-84. Available from: http://dx.doi.org/10.1016/j.injury.2014.01.003 
52. HUGHES CW. Arterial repair during the Korean war. Ann Surg. 1958;147(4):555-61.

53. Baylor Woodward ME, Colonel Darrin Clouse LW JEM, Michael Peck MA, Colonel Andrew Bowser LN, Mitchell Cox MW et al. Penetrating femoropopliteal injury during modern warfare: Experience of the Balad Vascular Registry. J Vasc Surg. 2008;47(6):1259-65.

54. Bible JE, McClure DJ, Mir HR. Analysis of single-incision versus dual-incision fasciotomy for tibial fractures with acute compartment syndrome. J Orthop Trauma. 2013;27(11):607-11.

55. Feliciano DV, Herskowitz K, O'Gorman RB et al. Management of vascular injuries in the lower extremities. J Trauma. 28(3):319-328.

56. Franz RW, Shah KJ, Halaharvi D, Franz ET, Hartman JF, Wright ML. A 5-year review of management of lower extremity arterial injuries at an urban level i trauma center. J Vasc Surg [Internet]. 2011;53(6):1604-10. Available from: http://dx.doi.org/10.1016/j.jvs.2011.01.052

57. T.C. Fabian, M.L. Turkleson, T.L. Connelly et al. Injury to the popliteal artery. Am J Surg. 1982;143:225-8. 